\title{
Calcifications in Thyroid Tumors on Ultrasonography: Calcification Types and Relationship with Histopathological Type
}

\section{(ㄷ) (1) $(2) \Theta$}

\section{Authors}

Kaoru Kobayashi' ${ }^{1}$, Tomoko Fujimoto², Hisashi Ota², Mitsuyoshi Hirokawa3 ${ }^{3}$, Tomonori Yabuta4, Hiroo Masuoka4, Mitsuhiro Fukushima4, Takuya Higashiyama ${ }^{4}$, Minoru Kihara ${ }^{4}$, Yasuhiro Ito ${ }^{4}$, Akihiro Miya ${ }^{4}$, Akira Miyauchi ${ }^{4}$

\author{
Affiliations \\ 1 Department of Surgery, Kuma Hospital, Kobe, Japan \\ 2 Department of Clinical Laboratory, Kuma Byoin, Kobe, \\ Japan \\ 3 Department of Diagnostic Pathology, Kuma Hospital, \\ Kobe, Japan \\ 4 Department of Surgery, Kuma Byoin, Kobe, Japan
}

Key words

thyroid, tumor, ultrasound, histopahology, calcifications

$\begin{array}{lr}\text { received } & 04.10 .2017 \\ \text { revised } & 19.02 .2018 \\ \text { accepted } & 05.03 .2018\end{array}$

Bibliography

DOI https://doi.org/10.1055/a-0591-6070

Ultrasound Int Open 2018; 4: E45-E51

(c) Georg Thieme Verlag KG Stuttgart · New York

ISSN 2199-7152

Correspondence

Dr. Kaoru Kobayashi,

Kuma Hospital

Department of Surgery

8-2-35 Shimoyamatedori

Kobe, 650-0011

Japan

Tel.: + 81/78/371 3721, Fax: +81/78/3713645

kobayashi@kuma-h.or.jp

\section{ABSTRACT}

Purpose The purpose of the study is to clarify the prevalence of calcifications within thyroid tumors on ultrasonography as well as the relationship between the calcification and histopathological types.

Materials and Methods Calcifications were classified into 6 (or 8) types according to their shape, size, and region. The prevalence of calcifications and types were investigated in new outpatients and patients who underwent thyroid surgery.

Results Among 2,902 nodules in 2,678 new outpatients, 747 nodules (26\%) had calcifications. The types showed a wide distribution. Among 941 patients with papillary carcinoma (PC), 725 patients ( $77 \%$ ) had calcifications, and the types showed a wide distribution. 18 patients with the diffuse sclerosing variant of PC only showed punctate microcalcifications in the parenchyma ( $100 \%), 32$ patients with the cyst-forming type of PC mostly fragmentary and massive types (100\%), and 161 metastatic lymph nodes from PC mostly punctate microcalcifications and fragmentary types (48\%). Among 337 patients with follicular carcinoma, 79 patients (23\%) had calcifications, and the types were mostly fragmentary, massive, and egg-shell types. Among 41 patients with undifferentiated carcinoma, 33 patients ( $80 \%$ ) presented with calcifications, which were mostly the massive and egg-shell types. Among 137 patients with medullary carcinoma, 99 patients ( $72 \%$ ) had calcification, and the types showed a wide distribution. None of 173 patients with primary thyroid lymphoma had calcifications ( $0 \%$ ).

Conclusion Calcifications on ultrasonography can be one of the characteristic findings and a full understanding of the prevalence of calcifications and types will markedly contribute to the ultrasonic diagnosis of thyroid tumors.

\section{Introduction}

Ultrasound is a useful imaging modality for detecting and assessing thyroid nodules, and it is a key examination. Ultrasound findings of thyroid nodules, such as their shape, echogenicity, internal contents, margins, vascularity, and calcifications, are important for evaluating them. Calcifications are common findings within thyroid nodules, and various calcification types may be seen at various rates [1]. What is the real prevalence of calcifications detected by ultrasonography within thyroid tumors of outpatients and what are the various histopathological types of thyroid tumors? Are the calcification types on ultrasonography associated with histopathological types of thyroid tumors? It is of interest to investigate whether calcifications on ultrasonography can contribute to the ultrasonic diagnosis of thyroid tumors. 
The purpose of the study is to clarify the prevalence of calcifications within thyroid tumors on ultrasonography as well as the relationship between the calcification and histopathological types.

\section{Materials and Methods}

\section{Ultrasonography and calcifications}

Ultrasound examination was performed using the same 6 units of the TOSHIBA Aplio SSA-770 A ultrasound system with PLT-1204BX (7-14 MHz) and PLT-805AT (5-12 MHz) linear probes for all periods of this study. Ultrasonic diagnosis of thyroid tumors was performed using Kuma Hospital's ultrasound classification system (Kuma's USC, USC 1, 2 = benign; USC 3 = borderline; and USC 4, 5 = malignant) [2, 3]. All thyroid tumors were classified as benign, borderline or malignant at ultrasonic diagnosis. Among the many ultrasonographic findings, we evaluated the images of calcifications (strong echoes) of thyroid tumors. Non-specific foci [4] (= so-called indeterminate hyperechoic spots) that are clinically observed in a thyroid cyst ( = comet-tail sign), in the thymus that are ectopically present in the thyroid gland of juvenile patients (= pseudocalcifications), in the thyroid of Hashimoto's thyroiditis of old patients, in the thyroid after suppurative thyroiditis and trauma of the neck, or in the lymph node without any suspicion of disease were excluded. In this study, calcifications on ultrasonography were classified into 6 types according to their shape, size, and region. Furthermore, punctate microcalcifications and speckled type calcifications were divided into 2 subtypes according to their number: (1) a: punctate microcalcifications ( $<1 \mathrm{~mm})$, small number $(1-5)$, b: punctate microcalcifications, multiple ( $>6$ ), (2) a: speckled type calcification $(1 \leq<3 \mathrm{~mm})$, single, b: speckled type calcifications, multiple $(>2)$, (3) fragmentary type calcifications ( $\leq 3 \mathrm{~mm}$ ), (4) massive type calcifications (= course), (5) egg-shell type calcifications ( = rim-like peripheral calcifications), and (6) punctate microcalcifications in the parenchyma. - Fig. 1 shows the schemas and images of calcification types on ultrasonography.

\section{Inter-observer variability on ultrasonography}

Two board-certified fellows (KK, MF) of the Japan Society of Ultrasonics in Medicine (JSUM) and 6-8 to eight registered medical sonographers of the JSUM performed ultrasound examinations (it takes at least 5 years of clinical ultrasonography experience to be qualified as a board-certified fellow, and at least 3 years of clinical ultrasonography experience to be qualified as a registered medical

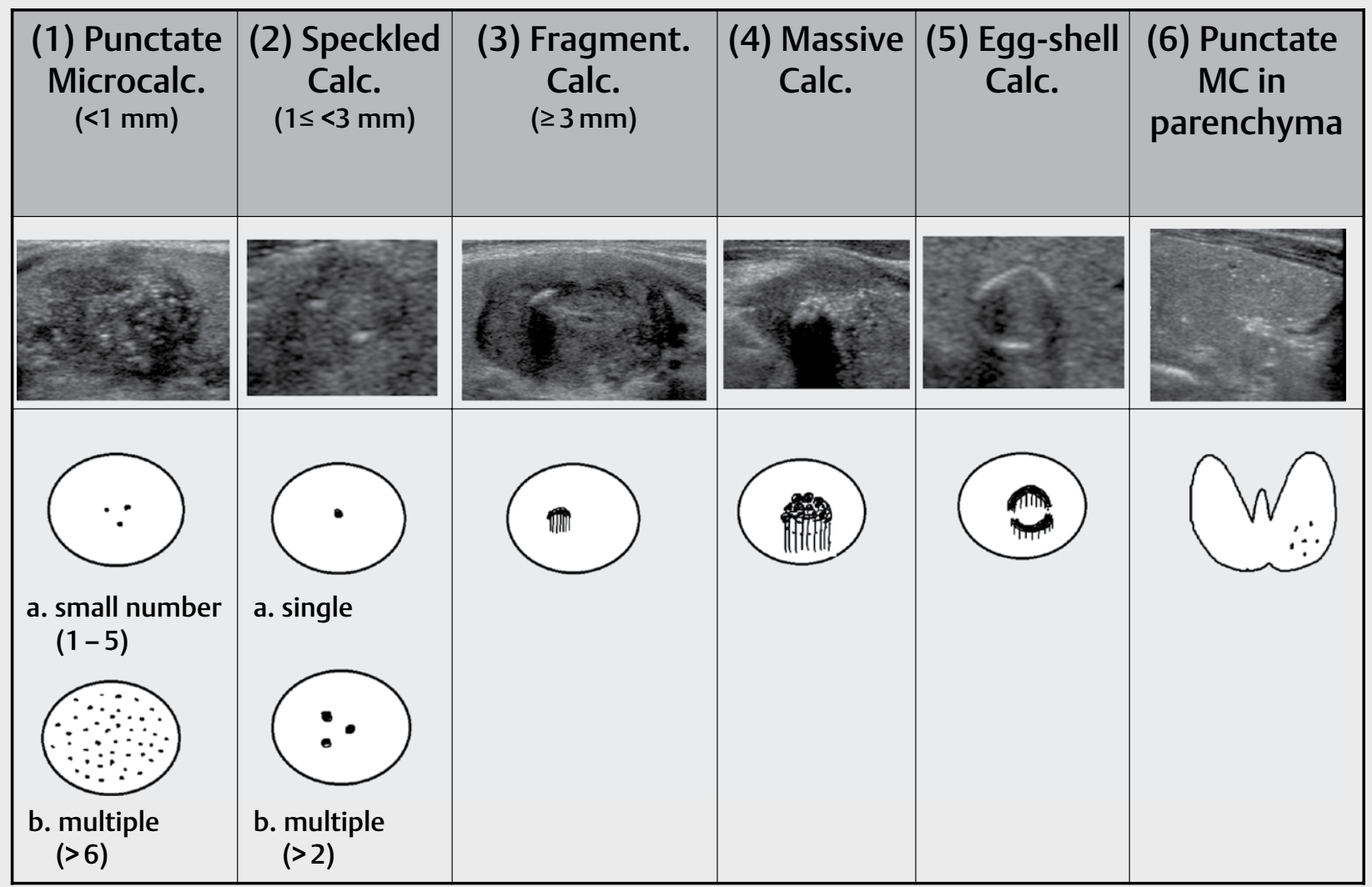

- Fig. 1 Classification of calcification types within thyroid nodules and parenchyma on ultrasonography. Calcifications on ultrasonography were classified into 6 types according to their shape, size, and region. Furthermore, punctate microcalcifications and speckled type calcifications were divided into two subtypes according to their number. (1) Punctate Microcalc.: punctate microcalcifications $(<1 \mathrm{~mm})$ a. small number (1-5). b. multiple (>6); (2) Speckled Calc.: speckled type calcifications $(1 \leq<3 \mathrm{~mm}$ ) a. single. b. multiple ( $>2)$; (3) Fragment. Calc.: fragmentary type calcifications ( $\geq 3 \mathrm{~mm}$ ); (4) Massive Calc.: massive type calcifications (= course); (5) Egg-shell Calc.: egg-shell type calcifications (= rim-like peripheral calcifications); (6) Punctate MC in parenchyma: punctate microcalcifications in the parenchyma. 
sonographer). We made it a rule to follow a standard scanning protocol to avoid missing clinically important lesions. The ultrasonic diagnoses were performed using the same ultrasound guidelines $[2,3]$ explained above. Clinicians, sonographers, and cytologists jointly took part in preoperative and postoperative conferences each week as part of the routine work of the hospital, and participated in an ultrasound conference each month to compare and adjust ultrasonic diagnosis in order to decrease interobserver variability [5].

\section{Investigation 1: Calcification within thyroid nodules in new outpatients}

We closely evaluated ultrasound images of thyroid nodules (maximum diameter of $5 \mathrm{~mm}$ or larger) of new outpatients who visited our hospital for 2 months between June and July 2013, and the calcification types on the ultrasound images of these patients were evaluated. Patients with thyroid nodules among these new outpatients subsequently underwent fine-needle aspiration cytology. Cytopathological diagnostic categories of thyroid nodules were based on the Bethesda system for reporting thyroid cytopathology [6]. Some patients among these new outpatients subsequently underwent thyroid surgery and the histopathological diagnosis was classified as benign or malignant. The relationship between the calcification type and ultrasonic diagnosis of new outpatients, cytopathological diagnostic category, and histopathological diagnosis was investigated. The prominent type of calcification from one nodule was used as a datum ( = nodule-based investigation) in investigation 1 , because we could prospectively observe the whole thyroid gland closely by scanning moving and static ultrasound images.

\section{Investigation 2: Calcification within thyroid tumors in patients who underwent thyroid surgery}

Four of the authors (KK, MF, TF, and $\mathrm{HO}$ ) performed the retrospective re-evaluation of ultrasound images that were extracted from the clinical database of the hospital. The investigated histopathological types of malignancy were as follows: (a) papillary carcinoma, (b) diffuse sclerosing variant of papillary carcinoma, (c) cyst-forming type of papillary carcinoma, (d) metastatic lymph nodes in the lateral neck from papillary carcinoma, (e) follicular carcinoma, (f) undifferentiated (anaplastic) carcinoma, (g) medullary carcinoma, and (h) primary thyroid lymphoma. In those with papillary carcinoma, we investigated the surgical patients for one year in 2013. We investigated metastatic lymph nodes in the lateral neck from papillary carcinoma in patients who had undergone primary surgery for papillary carcinoma in a period of 2 months between October and November 2013. In those with the other histopathological types of malignancy, we investigated the surgical patients for 9 years between 2005 and 2013. We used the same ultrasound machines for all periods of this study and were able to achieve the same quality of ultrasound images. Prominent calcification from one patient was used as a datum ( = patient-based investigation) in investigation 2, because static ultrasound images of main tumors could be retrospectively extracted from the clinical database of the hospital. The prevalence of calcifications and calcification types of thyroid malignancy were investigated.

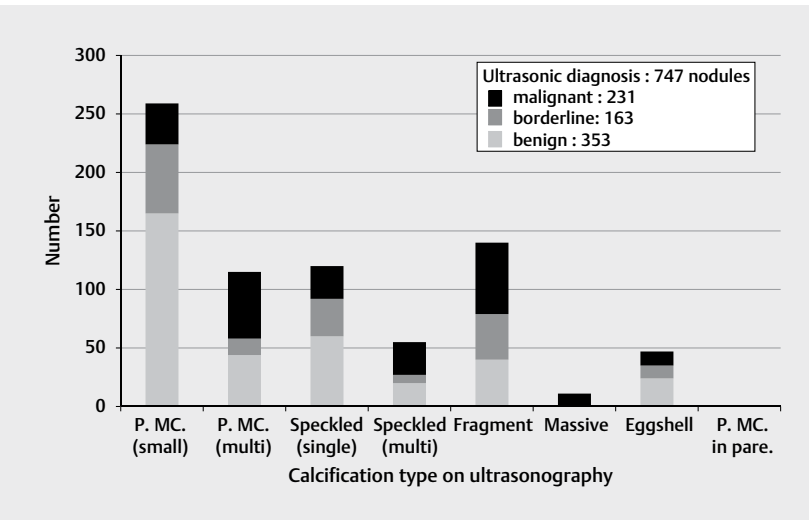

- Fig. 2 Relationship between calcification type on ultrasonography and ultrasonic diagnosis of thyroid nodules in new outpatients. Among 2,902 nodules in 2,678 new outpatients, 747 nodules (26\%) had calcifications and 2,155 nodules (74\%) did not. Ultrasonic diagnosis of thyroid nodules was performed using Kuma Hospital's ultrasound classification system (malignant, borderline, or benign). The relationship between the calcification type and ultrasonic diagnosis was investigated in these 747 nodules with calcifications.

\section{Histopathological diagnosis}

Histopathological diagnosis of thyroid tumors for all periods of this study was based on the histopathological criteria of the World Health Organization Classification of Tumors published in 2004 [7].

\section{Results}

\section{Investigation 1: Calcification within thyroid nodules in new outpatients}

Among 2,902 nodules in 2,678 new outpatients during the 2 months of June and July 2013,747 nodules ( $26 \%$ ) had calcifications and 2,155 nodules (74\%) did not. These 747 nodules with calcifications on ultrasonography were detected in 680 patients. > Fig. 2 presents the relationship between the calcification type and ultrasonic diagnosis (malignant, borderline, or benign) among these 747 nodules with calcifications. 231 nodules were diagnosed as malignant nodules, 163 nodules as borderline, and 353 nodules as benign. The calcification types showed a wide range.

Among these 747 nodules with calcifications, 560 nodules underwent fine-needle aspiration cytology. $>$ Fig. 3 presents the relationship between the calcification type and cytopathological diagnostic category among these 560 nodules with calcifications. 176 nodules were diagnosed as malignant, 21 nodules as suspicious of malignancy, 47 nodules as follicular neoplasm or suspicious for a follicular neoplasm, 10 nodules as atypia of undetermined significance or follicular lesion of undetermined significance, and 306 nodules as benign. The calcification types showed a wide range.

Among 2,678 new outpatients, 209 patients underwent thyroid surgery. 383 tumors were present in these 209 patients. Among these 383 tumors, 249 tumors (65\%) had calcifications and 134 tumors (35\%) did not. The relationship between the calcification type on ultrasonography and histopathological diagnosis (malignant or benign) was investigated in these 249 tumors with calcifications. 


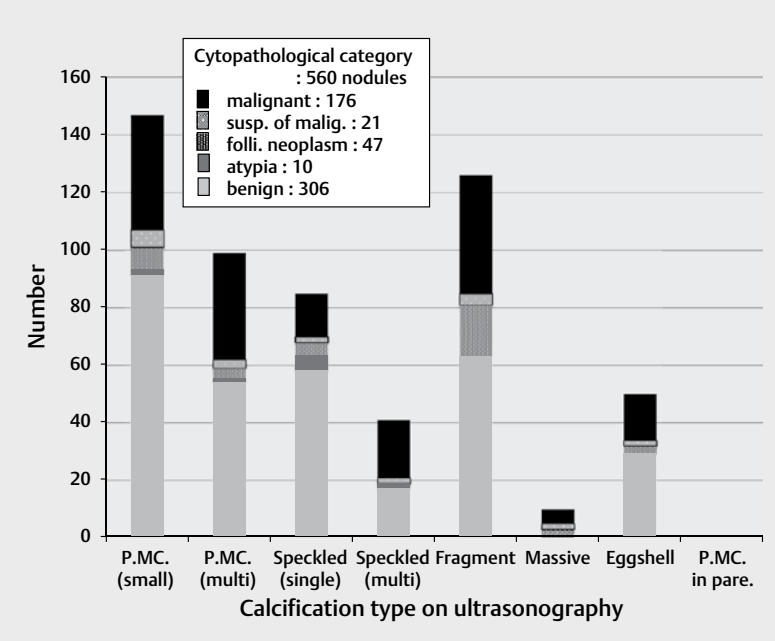

- Fig. 3 Relationship between calcification type on ultrasonography and cytopathological diagnostic category of thyroid nodules. Among 747 nodules with calcifications in 2,678 new outpatients, 560 nodules underwent the fine-needle aspiration cytology. Cytopathological diagnostic categories of thyroid nodules were based on the Bethesda system for reporting thyroid cytopathology. The relationship between the calcification type on ultrasonography and cytopathological diagnostic categories was investigated in these 560 nodules with calcifications. susp. of malig.: suspicious of malignancy, folli. neoplasm: follicular neoplasm or suspicious for a follicular neoplasm, atypia: atypia of undetermined significance or follicular lesion of undetermined significance.

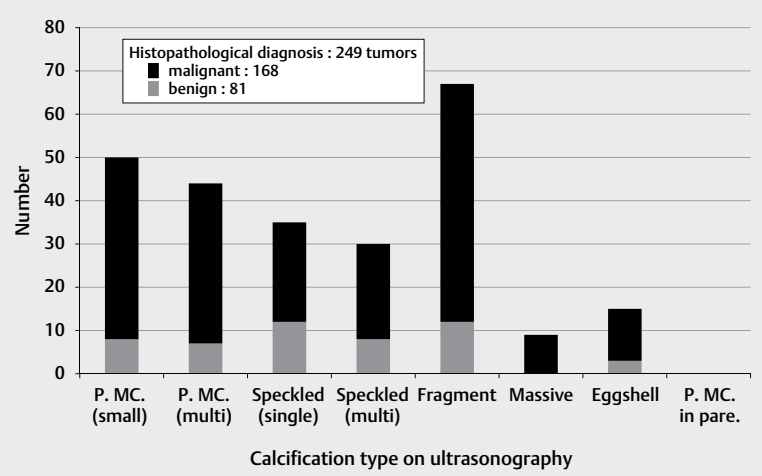

- Fig. 4 Relationship between calcification type on ultrasonography and histopathological diagnosis of thyroid tumors in surgical patients. Among 2,678 new outpatients, 209 patients underwent thyroid surgery. Three hundred and eighty-three tumors were present in these 209 patients. Among 383 tumors, 249 tumors (65\%) had calcifications and 134 tumors (35\%) did not. The relationship between the calcification type and histopathological diagnosis (malignant or benign) was investigated in these 249 tumors with calcifications. <malignant> papillary carcinoma: 164 tumors, medullary carcinoma: 2 tumors, follicular carcinoma: 2 tumors. <benign> multinodular goiters: 73 tumors, follicular adenoma: 8 tumors.

- Fig. 4 presents the relationship between the calcification type and histopathological diagnosis among these 249 nodules with calcifications. 168 tumors were diagnosed as malignant tumors: 164 papillary carcinomas, 2 medullary carcinomas, and 2 follicular car- cinomas. 81 nodules were diagnosed as benign tumors: 73 multinodular goiters and 8 follicular adenomas. The calcification types showed a wide range.

\section{Investigation 2: Calcification within thyroid tumors in patients who underwent thyroid surgery}

Among 941 patients with papillary carcinoma, 725 patients (77\%) had calcifications, and 216 patients ( $23 \%$ ) did not. The calcification types were investigated in these 725 patients with calcifications. - Table 1(a) presents the calcification types of papillary carcinoma. The calcification types showed a wide range. Punctate microcalcification (small number and multiple) made up $42 \%$ of the 725 patients with calcifications and $32 \%$ of all 941 patients with papillary carcinoma.

In all 18 patients with the diffuse sclerosing variant of papillary carcinoma, only multiple punctate microcalcifications in the parenchyma of the thyroid gland were observed ( $\triangleright$ Table $\mathbf{1}(\mathrm{b})$ )). The prevalence of calcifications was $100 \%$.

The calcification types of the cyst-forming type of papillary carcinoma were investigated. ( $\triangleright$ Table $\mathbf{1}(\mathrm{c})$ ) presents the calcification types of these 32 patients. The prevalence of calcifications was $100 \%$. Fragmentary (12 patients) and massive types (18 patients) of calcifications were mostly observed within the solid lesions, but the egg-shell type was not observed. Multiple punctate microcalcifications (1 patient) and a single speckled type calcification (1 patient) were also observed.

Metastatic lymph nodes in the lateral neck from papillary carcinoma were investigated. Among 203 dissected lymph nodes in 145 patients, 161 nodes showed metastasis and 42 nodes did not. Among these 161 nodes with metastasis, 78 nodes (48\%) had calcifications and 83 nodes (52\%) did not. The calcification types were investigated in these 78 nodes with calcifications. ( $>$ Table $\mathbf{1}(\mathrm{d})$ ) presents the calcification types of metastatic lymph nodes with calcifications. Multiple punctate microcalcifications (60 nodes) and fragmentary type calcifications (15 nodes) were predominantly observed. A single speckled type calcification (1 node) and eggshell type calcifications ( 2 nodes) were also observed, but massive type calcifications were not observed.

There were 337 patients with follicular carcinoma, 67 patients with the widely invasive type and 270 patients with the minimally invasive type. Among these 337 patients, 79 patients (23\%) had calcifications and 258 patients (77\%) did not. The calcification types were investigated in these 79 patients with calcifications. ( Table 1(e)) presents the calcification types of follicular carcinoma with calcifications. The calcification types were mostly the fragmentary, massive, and egg-shell types. The widely invasive type showed a significantly higher $(p<0.0001)$ prevalence of calcifications (41/67 patients, $61 \%$ ) than the minimally invasive type (38/270 patients, $14 \%$ ) (Chi-squared test, GraphPad InStat 3.1, GraphPad Software Inc.).

There were 41 patients with undifferentiated carcinoma. Among these 41 patients, 33 patients ( $80 \%$ ) presented with calcifications and 8 patients $(20 \%)$ did not. ( $\triangleright$ Table $\mathbf{1}(\mathrm{f})$ ) presents the calcification types of these 33 patients with calcifications. The calcification types were mostly the massive and egg-shell types.

There were 137 patients with medullary carcinoma. Among these 137 patients, 99 patients ( $72 \%$ ) had calcifications and 38 pa- 
- Table 1 Calcification type and prevalence of calcification on ultrasonography of malignant thyroid tumors and metastatic lymph nodes.

\begin{tabular}{|c|c|c|c|c|c|c|c|c|c|}
\hline & $\begin{array}{l}\text { P.MC. } \\
\text { (small) }\end{array}$ & $\begin{array}{l}\text { P.MC. } \\
\text { (multi) }\end{array}$ & $\begin{array}{l}\text { Speckled } \\
\text { (single) }\end{array}$ & $\begin{array}{c}\text { Speckled } \\
\text { (multi) }\end{array}$ & Fragment & Massive & Egg-shell & $\begin{array}{l}\text { P.MC.in } \\
\text { pare }\end{array}$ & $\begin{array}{l}\text { Prevalence of } \\
\text { calcification }\end{array}$ \\
\hline $\begin{array}{l}\text { (a) Papillary carcinoma (941 } \\
\text { patients) }\end{array}$ & 167 & 134 & 88 & 87 & 138 & 64 & 45 & 2 & $77 \%$ \\
\hline $\begin{array}{l}\text { (b) Diffuse sclerosing variant } \\
\text { of papillary carcinoma } \\
\text { (18 patients) }\end{array}$ & 0 & 0 & 0 & 0 & 0 & 0 & 0 & 18 & $100 \%$ \\
\hline $\begin{array}{l}\text { (c) Cyst-forming type of } \\
\text { papillary carcinoma } \\
\text { (32 patients) }\end{array}$ & 0 & 1 & 1 & 0 & 12 & 18 & 0 & 0 & $100 \%$ \\
\hline $\begin{array}{l}\text { (d) Metastatic lymph nodes } \\
\text { from papillary carcinoma } \\
\text { (161 nodes) }\end{array}$ & 0 & 60 & 1 & 0 & 15 & 0 & 2 & 0 & $48 \%$ \\
\hline $\begin{array}{l}\text { (e) Follicular carcinoma } \\
\text { ( } 337 \text { patients) } \\
\text { (widely } 67 \text { patients/mini } \\
270 \text { patients) }\end{array}$ & 0 & 0 & $\begin{array}{c}2 \\
(2 / 0)\end{array}$ & 0 & $\begin{array}{r}26 \\
(11 / 15)\end{array}$ & $\begin{array}{c}11 \\
(9 / 2)\end{array}$ & $\begin{array}{r}40 \\
(19 / 21)\end{array}$ & 0 & $\begin{array}{r}23 \% \\
(61 \% / 14 \%)\end{array}$ \\
\hline $\begin{array}{l}\text { (f) Undifferentiated } \\
\text { carcinoma ( } 41 \text { patients) }\end{array}$ & 1 & 0 & 1 & 1 & 0 & 12 & 18 & 0 & $80 \%$ \\
\hline $\begin{array}{l}\text { (g) Medullary carcinoma } \\
\text { (137 patients) }\end{array}$ & 29 & 15 & 13 & 21 & 14 & 7 & 0 & 0 & $72 \%$ \\
\hline $\begin{array}{l}\text { (h) Primary thyroid } \\
\text { lymphoma (173 patients) }\end{array}$ & 0 & 0 & 0 & 0 & 0 & 0 & 0 & 0 & $0 \%$ \\
\hline \multicolumn{10}{|c|}{$\begin{array}{l}\text { P.MC. (small): punctate microcalcifications }(<1 \mathrm{~mm}) \text {, small number }(1-5) \text {, P.MC. (multi): punctate microcalcifications }(<1 \mathrm{~mm}) \text {, multiple }(>6) \text {, } \\
\text { speckled (single): speckled type calcification }(1 \leq<3 \mathrm{~mm}) \text {, single, speckled (multi): speckled type calcifications }(1 \leq<3 \mathrm{~mm}) \text {, multiple }(>2) \text {, fragment: } \\
\text { fragmentary type calcifications ( } \geq 3 \mathrm{~mm}) \text {, massive: massive type calcifications (course), egg-shell: egg-shell type calcifications }(=\text { rim-like peripheral } \\
\text { calcifications), P.MC. in pare: punctate microcalcifications in the parenchyma, widely: widely invasive type of follicular carcinoma, mini: minimally } \\
\text { invasive type of follicular carcinoma }\end{array}$} \\
\hline
\end{tabular}

tients (28\%) did not. ( $\vee$ Table $\mathbf{1}(\mathrm{g})$ ) presents the calcification types of these 99 patients. The calcification types showed a wide range, but neither an egg-shell type calcification nor punctate microcalcifications in the parenchyma were observed.

There were 173 patients with primary thyroid lymphoma, 114 patients with mucosa-associated lymphoid tissue lymphoma and 59 patients with diffuse large B-cell lymphoma. ( sents the calcification types of these 173 patients. None of the patients had calcifications ( $0 \%)$.

\section{Discussion}

Calcifications are frequently found during the examination of thyroid ultrasonography, and various calcification types are seen within thyroid nodules and the parenchyma [1]. Also in this study, the rather high prevalence of calcifications (26\%) and the wide range of calcification types ( $\triangleright$ Fig. 1-4) were verified among thyroid nodules in new outpatients. Therefore, it is generally considered to be impossible to make a differential diagnosis for thyroid nodules by detecting calcifications alone. On the other hand, punctate microcalcifications on ultrasonography have been reported as an important characteristic for differentiating between malignant and benign nodules [8-13]. In our clinical experience, we have never seen calcifications in tumors of primary thyroid lymphoma or metastatic carcinoma to the thyroid gland from renal cell carcinoma [14]. Assessing calcifications as well as other characteristic findings can be helpful in making an ultrasonic diagnosis of thyroid tumors.

In this study, none of the follicular carcinoma lesions had multiple punctate microcalcifications ( $\triangleright$ Table $\mathbf{1}(\mathrm{e})$ ). This is consistent with the description in the comprehensive review by Grani G. et al. [15]. Therefore, we should consider papillary carcinoma and follicular carcinoma separately when making an ultrasonic diagnosis of thyroid tumors according to the calcification type. Multiple punctate microcalcifications are often shown in benign ( $>$ Fig. 2-4) and malignant tumors ( $\triangleright$ Fig. 2-4, $\triangleright$ Table 1 ). To make a correct diagnosis of tumors with multiple punctate microcalcifications, it is necessary to assess the other ultrasonographic findings together with the cytopathological appearance.

In the diffuse sclerosing variant of papillary carcinoma, calcifications solely presented as multiple punctate microcalcifications in the parenchyma of one or both lobes of the thyroid ( $\triangleright$ Table 1(b)), and distinct nodules were not observed within the thyroid. When multiple punctate microcalcifications within the thyroid parenchyma and bead-like swollen lymph nodes in the neck are found in young women [16], we should consider this disease the top differential diagnosis. 
The cyst-forming type of papillary carcinoma has a characteristic appearance [13], which is a large cyst, and solid lesions protrude into the cyst. Calcifications within a solid lesion are mostly the fragmentary and massive types, but the egg-shell was not observed $(\triangleright$ Table 1(c)). Such types of calcifications as well as other findings are characteristic in all patients with this type of papillary carcinoma.

The well-known ultrasonographic features of metastatic lymph nodes from papillary carcinoma are a rounded or irregular shape, heterogeneous and hyperechoic internal echo, a large cystic space, loss of a hyperechoic central hilum, abundant blood signals penetrating the node from the periphery, and the presence of calcifications $[8,17]$. In this study, calcifications mostly presented as 2 types, multiple punctate microcalcifications and fragmentary type calcifications ( $\triangleright$ Table $\mathbf{1}(\mathrm{d})$ ).

Calcifications of follicular carcinoma mostly presented as the following 3 types: fragmentary, massive, and egg-shell type calcifications ( $\triangleright$ Table $\mathbf{1}(\mathrm{e})$ ). The reported ultrasonographic features in follicular carcinoma $[15,18-22]$ as well as the calcification types will be helpful in diagnosing follicular carcinoma in combination with the cytopathological findings of follicular neoplasm.

Calcifications of undifferentiated carcinomas mostly presented as 2 types, the massive and egg-shell types ( Table $\mathbf{1}(\mathrm{f})$ ). Strictly speaking, it is most likely that calcifications in patients with undifferentiated carcinomas are not located in the tissues of the undifferentiated carcinoma. Instead, they are usually located in the tissues of a preceding well-differentiated carcinoma on the periphery. This observation indicates the following important point in ultrasonic diagnosis: when a tumor with a large solid-and-hypoechoic lesion as well as massive [23] or egg-shell type calcifications on the periphery is observed, we should try to acquire neoplastic cells from the large solid-and-hypoechoic lesion rather than the calcified lesion on the periphery when performing fine-needle aspiration cytology.

Calcifications in medullary carcinomas are hypothesized to be derived from amyloid deposits [24-26]. Medullary carcinomas have a wide range of calcification types on ultrasonography ( $\triangleright$ Table $\mathbf{1}(\mathrm{g})$ ). However, the egg-shell type calcification is not observed. These fragmentary calcifications are located in a comparatively central area of the tumor instead of in the periphery. These findings can be viewed as characteristic features of medullary carcinomas.

The absence of calcifications ( $\triangleright$ Table $\mathbf{1}(\mathrm{h})$ ) as well as an irregular border, markedly hypoechoic internal echoes, and enhanced posterior echoes may be characteristic features for the ultrasonic diagnosis of primary thyroid lymphoma [27].

The prevalence and types of calcifications were clarified in new outpatients, and had an association with the histopathological type of patients who underwent thyroid surgery. Therefore, assessing calcifications on ultrasonography is expected to contribute to the ultrasonic diagnosis of thyroid tumors. It should be noted that not all thyroid tumors have calcifications, but calcifications as well as other findings on ultrasonography have an important predictive value for the diagnosis of thyroid tumors.

The number of criteria needed to predict malignancy has been discussed [28]. On the whole, ultrasound features, such as tallerthan-wide shape, irregular margin, hypoechogenicity, presence of microcalcifications, and intravascular vascularity, can be useful di- agnostic criteria for predicting malignancy. That is because papillary carcinomas that present such typical features comprise the majority of thyroid malignancies. However, when we perform ultrasound examination of each patient, it is necessary to read and interpret other characteristic features such as tumor thrombus [19], tumor protrusion [20], or "nodule in nodule" appearance [21] to predict malignancy. Also, calcifications together with a specific ultrasound appearance such as cyst-forming [13] or diffuse swelling gland [16] should be noted for differential diagnosis in each patient.

Strain ultrasound elastography has recently been introduced in the clinical workup of thyroid nodules, and is an ultrasound-based technique for assessing the biomechanical properties of tissue. It is said that strain ultrasound elastography for the characterization of thyroid nodules in expert hands may be considered a useful complement to grayscale ultrasonography by enhancing its accuracy for thyroid malignancy detection [29]. However, it has some limitations such as inherent technical limitations as well as the histopathological features of the nodules themselves. These limitations may lead to misinterpretations and pitfalls [29]. More work on strain ultrasound elastography is expected in the future in order to overcome the limitations.

\section{Conflict of Interest}

The authors declare that they have no conflict of interest.

References

[1] Kakkos SK, Scopa CD, Chalmoukis AK, Karachalios DA, Spiliotis JD, Harkoftakis JG, Karavias DD, Androulakis JA, Vagenakis AG. Relative risk of cancer in sonographically detected thyroid nodules with calcifications. J Clin Ultrasound 2000; 28: 347-352

[2] Yokozawa T, Miyauchi A, Kuma K, Sugawara M. Accurate and simple method of diagnosing nodules the modified technique of ultrasound-guided fine needle aspiration biopsy. Thyroid 1995; 5: 141-145

[3] Ito Y, Amino N, Yokozawa T, Ota H, Ohshita M, Murata N, Morita S, Kobayashi K, Miyauchi A. Ultrasonographic evaluation of thyroid nodules in 900 patients: Comparison among ultrasonographic, cytological, and histological findings. Thyroid 2008; 17: 1269-1276

[4] Gharib H, Papini E, Garber JR, Duick DS, Harrell M, Hegedues L, Paschke R, Valcavi R, Vitti P.on behalf of the AACE/ACE/AME Task Force on Thyroid nodules. American association of clinical endocrinologists, American college of endocrinology, and Associazione medici endocrinology medical guidelines for clinical practice for diagnosis and management of thyroid nodules - 2016 update Appendix. Endocr Pract 2016; 22 (Suppl 1): 1-60

[5] Cantisani V, D’Ambrosio F, Bechmann M, Nielsen MB. Multiparametric ultrasound of thyroid nodules: Where we stand? Ultraschall in Med 2017; 38: 357-359

[6] Cibas Es, Ali SZ. The Bethesda system for reporting thyroid cytopathology. Thyroid 2009; 19: 1159-1165

[7] DeLellis RA, Lloyd RV, Heitz PU, Eng C. Pathology and genetics of Tumours of endocrine organs. World Health Organization classification of tumours. Lyon: IARC Press; 2004 
[8] Haugen BR, Alexander EK, Bible KC, Bible KC, Doherty GM, Mandel S], Nikiforov YE, Pacini F, Randolph GW, Sawka AM, Schlumberger M, Schuff KG, Sherman SI, Sosa JA, Steward DL, Tuttle RM, Wartofsky L. The American Thyroid Association (ATA) guidelines taskforce on thyroid nodules and differentiated thyroid cancer. 2015 American Thyroid Association management guidelines for adult patients with thyroid nodules and differentiated thyroid cancer. Thyroid 2016; 26 : $1-133$

[9] Gharib H, Papini E, Paschke R, Duick DS, Valcavi R, Hegedüs L, Vitti P.AACE/AME/ETA Task Force on Thyroid Nodules. American Association of Clinical Endocrinologists, Associazione Medici Endocrinologi, and European Thyroid Association medical guidelines for clinical practice for the diagnosis and management of thyroid nodules. J Endocrinol Invest 2010; 33 (5 Suppl): 1-50

[10] Dralle H, Musholt T], Schabram J, Steinmüller T, Frilling A, Simon D, Goretzki PE, Niederle B, Scheuba C, Clerici T, Hermann M, Kußmann J, Lorenz K, Nies C, Schabram P, Trupka A, Zielke A, Karges W, Luster M, Schmid KW, Vordermark D, Schmoll HJ, Mühlenberg R, Schober O, Rimmele H, Machens A.German Societies of General and Visceral Surgery; Endocrinology; Nuclear Medicine; Pathology; Radiooncology; Oncological Hematology; and the German Thyroid Cancer Patient Support Organization Ohne Schilddrüse leben e.V.. German Association of Endocrine surgeons practice guideline for the surgical management of malignant thyroid tumor. Langenbecks Arch Surg 2013; 398: 347-375

[11] Smith-Bindman R, Lebda P, Feldstein VA, Sellami D, Goldstein RB, Brasic N, Jin C, Kornak J. Risk of thyroid cancer based on thyroid ultrasound imaging characteristics: Results of a population-based study. JAMA Intern Med 2013; 173: 1788-1796

[12] Kwak JY, Han KH, Yoon JH, Moon HJ, Son EJ, Park SH, Jung HK, Choi JS, Kim BM, Kim EK. Thyroid imaging reporting and data system for US features of nodules: A step in establishing better stratification of cancer risk. Radiology 2011; 260: 892-899

[13] Henrichsen TL, Reading CC, Charboneau JW, Donovan DJ, Sebo TJ, Hay ID. Cystic change in thyroid carcinoma: Prevalence and estimated volume in 360 carcinomas. J Clin Ultrasound 2010; 38: 361-366

[14] Kobayashi K, Hirokawa M, Yabuta T, Fukushima M, Masuoka H, Higashiyama T, Kihara M, Ito Y, Miya A, Amino N, Miyauchi A. Metastatic carcinoma to the thyroid gland from renal cell carcinoma: role of ultrasonography in preoperative diagnosis. Thyroid Res 2015; 8: 4

[15] Grani G, Lamartina L, Durante C, Filetti S, Cooper D. Follicular thyroid cancer and Huerthle cell carcinoma: Challenges in diagnosis, treatment, and management. doi: 10.1016/S2213-8587(17)30325-X

[16] Kobayashi K, Fukata S, Amino N, Miyauchi A. A case with diffuse sclerosing variant of papillary carcinoma of the thyroid: Characteristic features on ultrasonography. J Med Ultrasonics 2006; 33: 159-161

[17] Sohn YM, Kwak JY, Kim EK, Moon HJ, Kim SJ, Kim MJ. Diagnostic approach for evaluation of lymph node metastasis from thyroid cancer using ultrasound and fine-needle aspiration biopsy. Am J Roentgenol 2010; 194: 38-43

[18] Kobayashi K, Fukata S, Miyauchi A. Diagnosis of follicular carcinoma of the thyroid: role of sonography in preoperative diagnosis of follicular nodules. J Med Ultrasonics 2005; 32: 153-158
[19] Kobayashi K, Hirokawa M, Yabuta T, Fukushima M, Kihara M, Higashiyama T, Tomoda C, Takamura Y, Ito Y, Miya A, Amino N, Miyauch A. Tumor thrombus of thyroid malignancies in veins: Importance of detection by ultrasonography. Thyroid 2011; 21: 527-531

[20] Kobayashi K, Hirokawa M, Yabuta T, Masuoka H, Fukushima M, Kihara M, Higashiyama T, Ito Y, Miya A, Amino N, Miyauchi A. Tumor protrusion with intensive signals on ultasonograhy is a strongly suggestive finding of follicular thyroid carcinoma. Med Ultrason 2016; 18: $422-427$

[21] Kobayashi K, Ota H, Hirokawa M, Masuoka H, Fukushima M, Kihara M, Higashiyama T, Ito Y, Miya A, Amino N, Miyauchi A. "Nodule in nodule" on thyroid ultrasonography: Possibility of follicular carcinoma transformed from benign thyroid tumor. Eur Thyroid J 2017; 6 : 101-107

[22] Sillery JC, Reading C, Charboneau JW, Henrichsen TL, Hay ID, Mandrekar JN. Thyroid follicular carcinoma: Sonographic features of 50 cases. AJR Am J Roentgenol 2010; 194: 44-54

[23] Kim S], Kwak JY, Hong SW, Kim EK, Kim M], Park SH, Son E], Park CS, Chung WY. Anaplastic thyroid carcinoma arising from a calcified thyroid mass. J Clin Oncol 2008; 26: 3800-3802

[24] Trimboli P, Giovanella L, Valabrega S, Andrioli M, Baldelli R, Cremonini N, Rossi F, Guidobaldi L, Barnabei A, Rota F, Paoloni A, Rizza L, Fattorini G, Latini M, Ventura C, Falasca P, Orlandi F, Crescenzi A, D'Ambrosio F, Cantisani V, Romanelli F, Negro R, Saggiorato E, Appetecchia M, Lilienfeld HS, Mclver B. Ultrasound features of medullary thyroid carcinoma correlate with cancer aggressiveness: A retrospective multicenter study. J Exp Clin Cancer Res 2014; 33: 87

[25] Zhou L, Chen B, Zhao M, Zhang H, Liang B. Sonographic features of medullary thyroid carcinomas according to size: Comparison with papillary thyroid carcinomas. J Ultrasound Med 2015; 34: 1003-1009

[26] Valderrabano P, Klippenstein DL, Tourtelot JB, Ma Z, Thompson Z], Lilienfeld HS, Mclver B. New ATA sonographic patterns for thyroid nodules perform well in medullary thyroid carcinoma: Institutional experience, systematic review and meta-analysis. Thyroid 2016; 26: 1093-1100

[27] Sharma A, Jasim S, Reading CC, Ristow K, Villasboas Bisneto ], Habermann T, Fatourechi V, Stan MN. Clinical presentation and diagnostic challenges of thyroid lymphoma - a cohort study. Thyroid 2016; 26: 1061-1067

[28] Ozel A, Erturk SM, Ercan A, Ercan A, Yilmaz B, Basak T, Cantisani V, Vask M, Karpat Z. The diagnostic efficacy of ultrasound in characterization for thyroid nodules: How many criteria are required to predict malignancy? Med Ultrason 2012; 14: 24-28

[29] Cantisani V, Grazhdani H, Drakonaki E, D’Andrea V, Di Segni M, Kaleshi E, Callida F, Catalano C, Redler A, Brunese L, Drudi FM, Fumarola A, Carbotta G, Frattaroli F, Di Leo N, Ciccariello M, Caratozzolo M, D'Ambrosio F. Strain US elastography for the characterization of thyroid nodules: Advantages and limitation. Int J Endocrinol 2015; 2015: 908575 